Rev. Interd. em Cult. e Soc. (RICS), São Luís, v. 6, n. 1, p. 23- 35, jan./jun. 2020

ISSN eletrônico: 2447-6498

\title{
A Mente de uma Maranhense Transgressora, Esta Ninguém Pode Escravizar: Vida e Obra de Maria Firmina dos Reis como Retrato da Condição Feminina no Século XIX ${ }^{1}$
}

\section{The Mind of a Transgressor Maranhense, Nobody Can Slave: Maria Firmina dos Reis'Life and Production as a Portrait of the Female Condition in the 19rh Century}

\author{
PATRICIA FERNANDA MASSETTI DE LIMA \\ Bolsista PIBIC do Curso de Letras Português/Espanhol da UEMA \\ paty.lima428@gmail.com
}

CAMILA MARIA SILVA NASCIMENTO Doutora em Ciências da Literatura pela UFRJ. Profa. Titular da UEMA letrascm@yahoo.com.br

\begin{abstract}
"Mesquinho e humilde livro é este que vos apresento leitor. Sei que passará entre o indiferentismo glacial de uns e o riso mofador dos outros, e ainda assim o dou a lume”.
\end{abstract}

(REIS, 2009, p.5)

\section{RESUMO}

Maria Firmina dos Reis, natural de São Luís - Maranhão, foi uma relevante personalidade maranhense do século XIX. Atribui-se a ela a criação da primeira escola pública mista do Estado. Na literatura, sua "boa morada", ingressou ao publicar o romance Úrsula (1859), defendido, por boa parte dos teóricos, como o primeiro romance genuinamente brasileiro, requisitos para que ela seja reconhecida como autora feminina que surgiu em um universo pensado exclusivamente pelo masculino. Discute-se, neste estudo, os motivos pelos quais Firmina não é reconhecida pelo cânone literário. Para tanto, foram visitadas produções de autores como Nascimento de Morais Filho (1975), Kothe (2001), Silva (2013) e Adler (2015) que pontuam prováveis causas do ostracismo a que Firmina foi relegada até meados da década de 70. Hoje, quase 160 anos após sua primeira publicação, sem influência direta do patriarcalismo, busca-se difundi-la como notável e relevante personalidade maranhense.

Palavras-chave: Escrita Feminina. Romance Maranhense. Patriarcalismo.

\begin{abstract}
Maria Firmina dos Reis, a native of São Luís - Maranhão, was a relevant 19th Century personality, is attributed to her the creation of the first public school in the state. On literature, her "good home", she entered by publishing the novel Úrsula (1859), defended by theorists as the first genuinely Brazilian novel, requirements for her to be recognized as a female author who emerged in a universe thought exclusively by the masculine. This study discusses the reasons why Firmina is not considered by the literary canon, therefore, authors' productions were visited such as Nascimento de Morais Filho (1975), Kothe (2001), Silva (2013) and Adler (2015); they punctuate probable causes of the ostracism to which Firmina was relegated until the mid-1970's. Today, almost 160 years after her first publication, without direct influence from patriarchalism, seeks to spread her as a remarkable and relevant Maranhão personality.
\end{abstract}

Keywords: Female Writing. Romance Maranhense. Patriarchy.

\footnotetext{
${ }^{1}$ Artigo submetido para avaliação em 10/10/2019 e aprovado em 20/10/2019.
} 
Rev. Interd. em Cult. e Soc. (RICS), São Luís, v. 6, n. 1, p. 23- 35, jan./jun. 2020

ISSN eletrônico: 2447-6498

\section{INTRODUÇÃO}

O contexto social no século XIX, não era favorável à inserção feminina no cenário literário. O patriarcalismo e o conservadorismo exacerbados exalam por todos os lados, a estratificação social impede determinados tipos de relações e o preconceito paira no ar como norteador das ações humanas. Nesse contexto, nasce Maria Firmina dos Reis no bairro de São Pantaleão, na província de São Luís do Maranhão.

Por ser um estudo recente, muitas divergências são observadas com relação a sua biografia. Sobre a data de nascimento, veiculada até meados de 2017 como dia 11 de outubro de 1825, segundo Adler (2018), após revisitada e citada no documento, atualmente, consta-se:

Diz Maria Firmina dos Reis, filha natural de Leonor Filippa dos Reis que ela quer justificar por este Juiso que nasceo no dia 11 de Março do anno de 1822, e que só teve lugar o seu baptismo no dia 211 de Desembro de 1825, ccomo mostra pelo documento junstos, por causa de moléstia que então lhe sobreveio e privou ser baptisada antes; o que feito requer se julgue por sentencia, e que mande abrir novo assento por tt. ${ }^{\circ}$ (Autos de justificação do dia de nascimento de Maria Firmina dos Reis, 25 de junho de 1847, Câmara Eclesiástica/Episcopal, série 26, Caixa n. 114 - Documento-autos no 4.171, ano 1847, 12 fls. Frente e Verso, In: ADLER, 2018, p.82)

Em sua filiação muitos pontos também são dissidentes. Onde antes se lia:

Leonor Fellipa, jovem branca, descendente de portugueses, remediada economicamente e desejada por parte da corte e João Esteves, um jovem negro e de poucas posses, sem atribuições de mais adjetivos. Daí infere-se qual era a sua posição social. Filha ilegítima de um relacionamento que a Igreja não abençoara, ela é recebida como a personificação do que se chama pecado. (NASCIMENTO \& LIMA, 2019, p.711, grifo nosso)

Após a publicação de Adler (2018), reportada ao livro de Batismo de nº116, Folha 182, compreende-se por sua filiação materna que Maria "é fillha legítima de Leonor Felippa, molata forra que foi escrava do Comendador Caetano[...]” (ADLER, 2018, p. 83). Com relação à filiação paterna, depreende apenas que "nos registros pesquisados consta o nome de João Pedro Esteves como seu pai no entanto nenhum outro dado é colocado sobre ele, salvo que é negro. Assim, a sua origem e vida são totalmente desconhecidas até hoje”. (ADLER, 2018, p. 83).

Ademais dessas questões, sabe-se que aos cinco anos de idade, aos cuidados de sua tia materna, mudou-se para o município de Guimarães e recebeu, naturalmente, o que podemos dizer uma educação “inferior” à dos meninos. Logo, impele ressaltar que parte do que aprendera procede de seu esforço e de sua dedicação pessoal. Ela, desde muito jovem, dedicou-se à leitura, às artes literárias e à licenciatura.

Grandes feitos são atribuídos a sua biografia: ter sido responsável pela idealização e fundação da primeira escola mista para meninos e meninas no estado do Maranhão (MORAIS 
Rev. Interd. em Cult. e Soc. (RICS), São Luís, v. 6, n. 1, p. 23- 35, jan./jun. 2020

ISSN eletrônico: 2447-6498

FILHO, 1975; MUZART, 2000; RUFINO, 1987 apud ADLER, 2015; LOBO, 1993). Fora a sua contribuição para a educação pública no município de Guimarães, ela é responsável por uma vasta produção poética, sendo de sua autoria o primeiro romance de ficção genuinamente brasileiro, Úrsula. Entretanto, ainda que de relevância literária e social, Firmina teve sua produção hostilizada, desmerecida e seus feitos ignorados até quase o final do século XX, devido, principalmente, a sua descendência e condição social de mulher - considerada um ser abjeto.

Por que estudá-la? O resgate e renascimento de seu nome para as letras foram obras de José Nascimento de Morais Filho (1975), que encontrou registros de sua escritura quando realizava uma pesquisa na Biblioteca Pública Benedito Leite. Apresentá-la e divulgar sua produção literária é papel de pesquisadores. Segundo expressa Adler (2015), "tardou essa bendita hora desse gênio das letras maranhenses". Adler continua dizendo:

O caminho de um precursor não é cousa fácil de se cumprir. Numa sociedade patriarcalista, e altamente conservadora, uma precursora sofrerá duplamente, principalmente se tiver na sua origem a ausência daquilo que Gonçalves Dias classificaria como 'sangue azul', e nem ser filha legítima. (ADLER, 2015, p.12)

Outra escritora maranhense, Arlete Nogueira da Cruz, no seu livro Sal e Sol (2006), registrou como feito histórico a realização de Morais Filho, mas advertiu que, ainda assim, a obra sofreu indiferentismo por parte de vários teóricos. Conforme ela,

Não fosse José Nascimento de Morais Filho, o nosso Zé Morais, este contumaz
andarilho de trilhas nunca antes percorridas, Maria Firmina dos Reis não teria vindo à
luz. E quando ele a trouxe (no momento em que também a trazia o escritor paraibano
Horácio Almeida), lembro bem, foram alvo de zombarias em São Luís: Zé Morais,
Maria Firmina e o seu livro Úrsula; muitos considerando que era de pouca serventia
aquele achado e exagerada a relevância que Zé Morais dava à sua descoberta. (CRUZ,
2006, p.265)

Segundo Mendes (2012), a concepção renovada da historiografia, permitida pela Escola dos Analles, pretendeu ampliar o leque de fontes e observar a presença de pessoas comuns na formação da História. Assim, as mulheres passam a ser entendidas, sobretudo, como agentes históricos. Dessa forma, tornou-se possível escrever uma história que incluísse a mulher como realizadora de parte dos feitos, não observando apenas as grandes realizações e protagonismo masculino.

Nas palavras de Suely Costa (2003, p. 199), expressas por Janaina Correia (2013, p. 3), "só por admiti-las como sujeitos históricos, coloca-se de pernas para o ar muitas certezas e modelos universais de análises dos sistemas de poder e subordinação nas relações sociais de 
Rev. Interd. em Cult. e Soc. (RICS), São Luís, v. 6, n. 1, p. 23- 35, jan./jun. 2020

ISSN eletrônico: $2447-6498$

qualquer tipo". Percebe-se com isso como a historiografia dos Analles contribuiu de forma incisiva não só para a percepção e tentativa de inserção/aceitação de Maria Firmina dos Reis no cenário literário nacional, mas também nas concepções políticas com as quais ela se envolveu.

É conveniente ressaltar que essa prática contribuiu como fator decisivo da postura firminiana diante do contexto abolicionista no papel, mas escravocrata na prática. Por conta disso, suas primeiras produções não receberam a assinatura direta da autora. Por vezes ela assinava como "um maranhense" ou, anos depois, apenas como "MFR". O motivo principal seria a desqualificação que teriam as suas produções para o contexto, se assinadas por uma mulher.

Quanto a isso, Adler (2015) deixa registrado no Posfácio do livro de autoria de Nascimento (2011) que "a criatividade, como qualquer outro traço ou característica humana, necessita de condições adequadas para que possa se desenvolver". Ela explicita que o contexto em que determinada personalidade está inserida, além de fatores intrapessoais e interpessoais, aspectos decisivos para a sua produção, é o "der Gheist der Zeit" ou "espírito da época". Neste aspecto, mais uma vez Firmina coloca-se em condição oposta, visto que, por mais que visse suas produções sendo hostilizadas, não deixou de produzi-las.

Segundo Kothe (2001), os motivos para que uma obra seja eleita cânone, em detrimento de outra tão ou até mais forte, são políticos. Por motivos politiqueiros e vanguardistas, obras espirituosas são deixadas à margem. No caso de Úrsula, principal romance de Firmina, muitos são os motivos: mulher e mulata como autora, numa sociedade escravocrata e patriarcal, era inadmissível.

Para ser socialmente aceita no cânone, a trajetória de Maria Firmina foi bastante conturbada, pois, para que de fato houvesse a representação de uma mulher real, como ela, nas Letras, anos e anos de exclusão, teriam que ser consideradas as duas vezes em que ela nasceu: a primeira, em 1825, e a segunda, um século e meio depois, pelas mãos de Morais Filho. Em ambas ela foi igualmente rejeitada pela sociedade preconceituosa e segregária, incluindo alguns teóricos que, ainda hoje, não reconhecem seu valor e o valor daquilo que ela escreveu.

Demonstrar o seu valor, sobretudo, percebendo que Maria Firmina protagonizou sua história, dando várias respostas para a sociedade quando esta a rejeitou, nos impele, a nós, amantes da literatura e pesquisadores da produção brasileira e maranhense, que garimpemos esses e outros escritos de gênero feminino, para valorizar e resgatar as vozes há tanto caladas pelo discurso masculino. 
Rev. Interd. em Cult. e Soc. (RICS), São Luís, v. 6, n. 1, p. 23- 35, jan./jun. 2020

ISSN eletrônico: 2447-6498

\section{MARIA FIRMINA: OUSADIA E TRANSGRESSÃO}

No contexto histórico em que estava inserida essa maranhense, destaca-se, sobretudo, que o espaço reservado à mulher era restrito ao lar e às atividades domésticas. Colocar-se na contramão do que a sociedade da época impunha para o sexo feminino é assumir a real condição de transgressora. Foi nesse sentido que Maria Firmina dos Reis, mostrando-se dona e protagonista de sua história, eclodiu. Sua ousadia a faz tentar perpassar anos de práticas que excluíam a mulher, quando ela apresenta em sua obra assuntos contraditórios aos postulados à época, razão pela qual ficou no esquecimento, sendo, ainda hoje, pouco estudada e divulgada.

Nas palavras de Silva (2011), "Maria Firmina tinha clareza de que o lugar que tentava ocupar no mundo das letras era de difícil acesso para as mulheres". Justificam-se com isso suas palavras no prólogo de seu primeiro romance, Úrsula, em que pede desculpas aos leitores por ter escrito o livro. Ela própria denota conhecer com clareza que o lugar que tentava ocupar era de difícil acesso para as mulheres, por este motivo indica no prólogo de seu romance:

Sei que pouco vale este romance, porque escrito por uma mulher, e mulher brasileira de educação acanhada, sem trato e a conversação dos homens ilustrados, que aconselham, que discutem e que corrigem, com uma instrução misérrima, apenas conhecendo a língua de seus pais. (REIS, 1859, p.5)

A autocrítica registrada atinge não só o aspecto patriarcal, no cenário natural do século XIX, em que a figura masculina acabava por ser supervalorizada, mas atinge-nos também. Ainda que passados séculos de muitos avanços e conquistas, seu discurso e suas palavras se fazem atuais, sobretudo quando explicita seu gênero e nacionalidade. Ela é "mulher brasileira e mulher brasileira de educação acanhada, sem trato e a conversação dos homens ilustrados". A ideia que nos alcança é a de que, por ser uma brasileira, suas palavras também perdem valor.

Ressalta-se a intenção de Firmina ao desculpar-se com seus possíveis leitores. No entanto, o impacto causado pelas suas palavras, atualmente, perpassa pela discussão não somente de pedir licença à sociedade por ser mulher e escritora, mas, ao mesmo tempo, vem ao encontro de um empoderamento feminino adquirido. É como se dissesse: tire seu machismo do caminho que eu preciso passar com o meu saber e o meu conhecimento de mulher.

Há, por outro lado, uma crítica sutil à supervalorização que é dada à cultura estrangeira, que exalta artistas e obras como integrantes do seleto "cânone", enquanto obras que falam sobre nós e a nossa cultura são renegadas e esquecidas. Neste aspecto, o discurso de Firmina também se atualiza, tanto na perspectiva da menos-valia da identidade nacional, amplamente defendida e estudada um século depois com o Modernismo, quanto na perspectiva 
Rev. Interd. em Cult. e Soc. (RICS), São Luís, v. 6, n. 1, p. 23- 35, jan./jun. 2020

ISSN eletrônico: $2447-6498$

das teorias de gênero. Nesse sentido, nota-se que os títulos das maiores obras da Literatura Nacional ainda são de autoria masculina, porque os homens receberam, por muito tempo, o aval da sociedade.

Considerando o período oitocentista, a própria Maria Firmina registra conhecer os limites quando se trata de uma produção feminina. Neste aspecto, Silva (2011) declara: "contrariando a morfologia do termo, no século XIX, a palavra era masculina, e o que ficava para as mulheres era o silêncio". Essa afirmativa comprova, mais uma vez, que Firmina assume uma postura transgressora à época e evidencia as consequências que recairiam sobre a sua atitude.

Ainda que reconhecesse as barreiras que encontraria quando do lançamento do neófito romance, no dia 11 de agosto de 1860, um grupo de maranhenses leitores e que tinham acesso aos jornais receberam a seguinte notícia sobre o lançamento de Úrsula:

Acha-se à venda na Tipografia do Progresso, este romance original brasileiro, produção da Exma. Sra. D. Maria Firmina dos Reis, professora pública em Guimarães. Saudamos a nossa comprovinciana pelo ensaio que revela de sua parte bastante ilustração, e, com mais vagar, emitiremos a nossa opinião, que desde já afiançamos não será desfavorável à nossa distinta comprovinciana. (Jornal A Moderação. In: SILVA, 2011, p.12)

Nessa altura, Firmina já era professora concursada no município de Guimarães, ostentando em seus 34 anos uma vasta quantidade de projetos sociais em prol da educação e da participação feminina em outros segmentos, que não fossem casa, filhos e marido somente. Por conta da singularidade dos temas que tratava em suas obras e da singularidade de sua própria escrita, são poucas as menções feitas à autora no período em que foi lançado o seu livro, o que nos faz entender que a repercussão merecida não lhe foi dada.

A sociedade oitocentista preconizava que à mulher não podia ser dada outra função a não ser a de "administrar" o lar. Quanto a isso, em uma edição datada de 1871, o jornal $O$ Progresso publicou:

A mulher, delicada, amante, cria o filho, administra a casa. Isto quer dizer que a mulher não nasceu para literata; mas para mãe de família; e que não lhe é dada a disputar ao homem, se lhe é dado disputar alguma coisa aquele de quem tudo consegue e a quem tudo entrega, senão o amor de seus filhos. (Jornal O Progresso, 1871, In: SILVA, 2013, p. 110 - grifo nosso).

Quando destacamos "não nasceu para literata", choca-nos a expressão, principalmente, por confirmar que havia uma intrínseca relação/exclusão, isto é, se nascesse mulher, não poderia dedicar-se à escrita e produção; se nascesse homem, não poderia dedicar-se à casa e aos filhos. Tais palavras justificam o insucesso de Firmina e a não validação de sua obra 
Rev. Interd. em Cult. e Soc. (RICS), São Luís, v. 6, n. 1, p. 23- 35, jan./jun. 2020

ISSN eletrônico: 2447-6498

enquanto exemplo artístico e literário, legitimando a omissão de um cânone em potencial, que se tornou alheio por questões vãs e superficiais, consubstanciais ao regime patriarcal vigente na época.

\section{3 ÚRSULA: A VOZ DOS EXCLUÍDOS}

Ainda que tenha participado da roda dos enjeitados do cenário literário, a autora mostrou ao que veio por meio de uma produção engajada e de construção social relevante. Suas obras são um recorte do panorama heterogêneo da sociedade maranhense do período oitocentista. Úrsula (1859) é admitido por boa parte dos estudiosos da Literatura Ocidental como o primeiro romance genuinamente brasileiro (ALENCAR apud MORAIS, 1975).

Quanto ao romance, inicialmente nos deparamos com um enredo que não foge ao que estamos habituados, principalmente, ao se tratar da estética romântica: a presença de um jovem forte e bonito, uma moça virgem e amável, um vilão cruel e frio - uma história de amor cheia de altos e baixos. Até aí, uma construção habitual, porém a surpresa aparece quando nos deparamos com uma narrativa que contraria os parâmetros estatuídos pelo movimento da época. $\mathrm{Na}$ obra, as personagens principais não fazem parte de pares românticos como de costume, mas são os escravos que a protagonizam; retratos da condição do negro traficado, escravizado e sem voz.

No romance, somos conduzidos a conhecer a penúria escrava por que passam Túlio, Tancredo e Antero. A narrativa dá vez e voz aos personagens que falam de sua condição não com passividade assistida, submissa ou apenas lamentosa, como era visto em romances abolicionistas anteriores. Ela faz e apresenta um retrato da escravidão, mas com uma visão crítica, sempre indagando as condições e os motivos pelos quais estão nela.

$\mathrm{Na}$ obra, o discurso antiescravista é referido de maneira contundente pela personagem feminina, Preta Suzana que, no capítulo homônimo, fala com imenso discernimento sobre a sofrida diáspora africana e, melancolicamente, lembra-se de sua terra natal. No fragmento seguinte, ela, nostalgicamente, narra para o Túlio como era sua vida antes de ter sido tomada como escrava:

- Sim, para que lagrimas?!... Dizes bem! Ellas são inúteis, meo Deos; mas é um tributo de saudade, que não posso deixar de render a tudo quanto me foi caro! Liberdade! Liberdade... ali! Eu a gosei na minha mocidade! - 'continuou Susana com amargura' Tulio, meo filho, ninguém a gozou mais ampla, não houve mulher alguma mais ditosa do que eu. Tranquila no seio da felicidade, via despontar o sol rutilante e ardendo do meo pais, e louca de praser a essa hora matinal, em que tudo ahi respira amor, eu corria as descarnadas e arenosas praias, e ahi com minhas jovens companheiras, brincando alegres, com o sorriso nos lábios, a paz no coração, divagamos em busca das mil 
Rev. Interd. em Cult. e Soc. (RICS), São Luís, v. 6, n. 1, p. 23- 35, jan./jun. 2020

ISSN eletrônico: 2447-6498

conchinhas, que bordam as brancas areias d'aquellas vastas praias. Ah! Meo filho! (REIS, 1859, p. 133)

Na voz da Preta Suzana, o tom crítico permanece, essencialmente, quando ela comenta sobre o episódio de sua captura nas matas de sua pátria:

Ainda não tinha vencido cem braças do caminho quando um assobio, que repescutio nas mattas, me veio orientar acerca do perigo iminente, que ahi me aguardava. E logo dous homens appareceram, e amarraram-me com cordas. Era uma prisioneira - era uma escrava! Foi em balde que supliquei em nome de minha filha, que me restituíssem a liberdade: os bárbaros sorriam-se das minhas lagrimas e olhavam-me sem compaixão. Julguei enlouquecer, julguei morrer, mas não me foi possível... a sorte me reservava ainda longos combates. Quando me arrancaram d'aquelles lugares, onde tudo me ficava - pátria, mãe e filha, e liberdade! Meo Deus! O que se passou no fundo da minha alma, só vós o podestes avaliar!... (REIS, 1859, p. 135)

Nesse fragmento, as palavras da escrava perpassam o convencional - a expressão de revolta velada pelo que perdera: “pátria, esposo, mãe, filha e liberdade!”. Revela a consciência de sua condição, não aceitando passivamente o infortúnio de sua má sorte, mas revoltando-se contra aqueles que primeiro fizeram e propagaram o mal da escravidão.

Fora a questão dos sentimentos e do sofrimento psicológico do negro, inserido em um cenário de total instabilidade afetiva e miserabilidade emocional, Firmina dá à Preta Susana voz para denunciar as condições em que os traficados eram mantidos durante a vinda para a província:

\begin{abstract}
Metteram-me a mim e a mais trezentos companheiros de infortúnio e de cativeiro no estreito e infecto porão de um navio. Trinta dias de cruéis tormentos e de falta absoluta de tudo quanto é mais necessário à vida passamos n'essa sepultura até que abordamos às praias brasileiras. Para caber a mercadoria humana no porão fomos amarrados em pé e para que não houvesse receio de revolta, acorrentados como os animaes ferozes das nossas mattas, que se levam para recreio dos potentados da Europa: Davam-nos a água imunda, podre e dada com mesquinhez, a comida má e ainda mais porca: vimos morrer ao nosso lado muitos companheiros à falta de ar, de alimento e de água. É horrível lembrar que creaturas humanas tractem a seos semelhantes assim e que não lhes doa a consciência de leva-los à sepultura asphixiados e famintos! (REIS, 1859, p. 136)
\end{abstract}

Preta Susana continua seu discurso melancólico e repleto de absurdos, frisando que "a dor da perda da pátria, dos entes caros, da liberdade foi sufocada nessa viagem pelo horror constante de tamanhas atrocidades" (REIS, 1859, p. 136). Nesse fragmento, a escolha do verbo "sufocar" surpreende por conta de toda a carga, representação e projeção mentais negativas que ele representa. O sufocar de Suzana pôde ser sentindo por toda a sucessão de leitores que, em suas palavras, leram e perceberam a carga emotiva impressa.

Faz-se importante ressaltar que, ao fazer essa denúncia, a autora arrisca sua própria pele, uma vez que a obra vem a lume em 1859, embora desde 1850 já existisse a Lei Eusébio de 
Rev. Interd. em Cult. e Soc. (RICS), São Luís, v. 6, n. 1, p. 23- 35, jan./jun. 2020

ISSN eletrônico: 2447-6498

Queiroz. Ela proibia, terminantemente, o tráfico negreiro na província, entretanto sabe-se que, na prática, a realidade era outra; ainda que proibido, o tráfico existia, não de forma escancarada, mas clandestina. Nove anos após a promulgação da lei, permanece a denúncia do tráfico e daqueles que financiavam essa prática, colocando em condição temerária esse alerta.

Nesse viés, questionamos: qual o peso e o impacto que essa denúncia provocaria? Considerando o momento histórico em que é inserida, que reações poderiam gerar nos leitores, caso fosse divulgada? Além disso, na obra, o discurso é dado a uma personagem feminina, negra e escrava. Coincidência ou não, nos deparamos com personagens femininas que, mesmo vivendo num período altamente patriarcalista, têm voz e senso crítico, não mais aceitando as situações às quais são subjugadas.

Comprova-se, com os fragmentos acima, que a narrativa quebra a ideia construída culturalmente de que o posicionamento e altivez contra a escravidão deveriam ser, sobretudo, masculinos. Essa é uma novidade que Firmina traz para suas personagens femininas, cuja intenção é a de inseri-las em assuntos relevantes e que, direta ou indiretamente, as envolvem, merecendo discussões.

Outro exemplo desse intento é encontrado no conto A Escrava (1887), em que a fala abolicionista se faz altiva. No meio de um salão nobre, de maneira corajosa, uma senhora conta a vida de uma escrava. Ora, qual a necessidade de trazer para o seio elitista-patriarcal tal situação? Que valor teve para o contexto político-social da época essa relação crítico-discursiva da escritora?

Importante lembrar que temas dissidentes daqueles que a aristocracia erigia, como exemplo, os abolicionistas, causavam profunda insatisfação e desconforto. Vê-se representado no discurso de Firmina um retrato de tudo que fugia ao estatuído, sem dúvida, por se tratar da condição da que se disse: mulher e mestiça. Sua audaciosa postura serviu para desestabilizar estruturas, ainda que de maneira sutil, mas que fugiu ao proposto pelo discurso masculino. Para Hoock-Damarle (1991), apud Silva (2011), "tocar em assuntos tão sérios, como a escravidão ou a abolição, era reservado ao homem".

Maria Firmina dos Reis pariu uma obra carregada de denúncias, ainda que veladas pela ficção e linguagem metafórica. O resultado, entretanto, foi o ostracismo em que ela foi inserida. Por não conseguirem mantê-la calada antes de suas publicações, fizeram-na em seguida. Por esta razão, romances, poemas, contos e até o Hino à Libertação dos Escravos caíram no esquecimento literário e popular. Tanto que, até meados de 1970, nada se sabia sobre essa 
Rev. Interd. em Cult. e Soc. (RICS), São Luís, v. 6, n. 1, p. 23- 35, jan./jun. 2020

ISSN eletrônico: 2447-6498

maranhense que enfrentou as mais difíceis agruras de seu tempo, mas deu voz àquela que, por força de uma sociedade hipócrita, deveria ficar calada - a mulher negra.

\section{ABOLIÇÃO E IDEALIZAÇÃO}

Há no campo dos estudos literários a expressão "Der Gheist der Zeit", que se aproxima daquilo que compreendemos como espírito da época. É a resposta que os autores trazem àquilo que os circundava. Colocam em suas obras e produções fagulhas do que era visto cotidianamente por eles, sendo o produto final um importante objeto diacrônico de compreensão da sociedade.

Perceber a literatura como recurso para construir conhecimentos acerca do mundo, das ciências e da sociedade é validar a contribuição de personalidades, até então, desmemoriadas. Neste aspecto, Adler (2009) enfatiza o papel lírico de produções como as de Firmina:

[...] O poeta assim serve-se de recursos que impeçam o esquecimento das memórias que se tornaram indesejáveis pelas normas do coletivo intolerante gerando a censura, a qual resulta o recalcamento da verdade rejeitada incompatível com o convívio dos demais. Nesse sentido, o poeta busca o desnudamento, o desmascaramento, a quebra do espelho, a quebra dos ídolos, expressando a verdade negada, que por sua vez provoca as mais profundas transformações no homem e no seu meio (ADLER, Revista IHMG N.31, novembro de 2009 Ed. Eletrônica. 128 - 137).

Nota-se que a produção lírica é um recurso que facilita a compreensão da realidade e, ainda que haja a presença da ficção, não haverá de existir um caráter verídico. Sob essa concepção, destacam-se as produções poéticas de Firmina e sua função renovadora de concepções já existentes.

Em 1888, ao assinar a Lei Imperial de $\mathrm{N}^{\mathrm{o}} 3353$, a princesa regente, Maria Isabel, declarava livres todos os negros cativos. Nesse mesmo ano, a autora, dissonante da maioria dos aspectos projetados sobre as mulheres, compõe o Hino à libertação dos escravos. Uma ode ao sofrimento escravo, repleto da idealização acerca da vida do negro e de sua aceitação na sociedade a partir de sua liberdade:

Hino à Libertação dos escravos Salve Pátria do Progresso!

Salve! Salve Deus a Igualdade! Salve! Salve o Sol que raiou hoje, Difundindo a liberdade! Quebrou-se enfiam a cadeia Da nefanda Escravidão! Aquele que antes oprimia,

Hoje terás como irmão! Maria Firmina dos Reis (1888) 
Rev. Interd. em Cult. e Soc. (RICS), São Luís, v. 6, n. 1, p. 23- 35, jan./jun. 2020

ISSN eletrônico: $2447-6498$

Para Firmina, a partir daquele momento, novos horizontes surgiriam e os escravos poderiam, por fim, desfrutar de tudo aquilo que significasse uma nova vida. Idealizou-se um horizonte de mudanças, aceitação e melhoria na relação entre brancos e negros. Em parte, houve ingenuidade da autora ao acreditar que o motivo da segregação era apenas a questão da alforria, fato este comprovado quando diz: "aquele que antes oprimia, hoje terá como irmão". Percebe-se que há a projeção de um futuro sem escravidão e sem tudo aquilo que dela degringola: preconceito, marginalização, violência.

O que justifica esse fato não é apenas a visão idealizada que Firmina demonstrava ter, mas também o reflexo da escola literária em que se enquadrava: o Romantismo. Há com o Romantismo uma busca por idealizar fatos vistos como cotidianos, procurando amenizar o seu efeito negativo.

Quanto a isso, Silva (2013, p. 64) afirma que:

[...] o discurso antiescravista emerge e se faz forte principalmente através de uma literatura romântica, à qual Maria Firmina estava inserida. Uma literatura que pretendia formar um ideário de nação, de pátria e de civilização. Uma literatura que se dizia, pela primeira vez, essencialmente brasileira. Que buscava, como apontou Machado de Assis, um "instinto de nacionalidade". Ora, esse "instinto de nacionalidade" fez os românticos pensarem e repensarem a nação; ao fazerem isso, repensaram a condição do cativo e da escravidão.

O instinto de nacionalidade faz com que parte do que era escrito torne-se instrumento para construção de uma identidade que evoque a cultura nacional, não aceitando padrões impostos por outras nações, que, neste aspecto, não se aproximam em nada do Brasil.

Ainda que a Lei Áurea tenha sido instituída, o escravo permanecia em condição subalterna e, por não terem meios de sobreviver, muitos acabam sujeitando-se ao trabalho escravo novamente. O Hino à Libertação dos Escravos revela-se uma idealização de futuro, representando os anseios de parte da população antiescravista do Maranhão do século XIX. Firmina, mais uma vez, usa sua voz para disseminar o amor ao próximo, um dos principais princípios cristãos; mais uma vez tentou promover o pensamento crítico e fraterno como resposta para parte das mazelas que assolavam a sociedade.

\section{CONSIDERAÇÕES FINAIS}

Maria Firmina dos Reis foi uma voz que diferiu de tudo que se esperava da sua época, primeiro por ser mulher e negra, segundo por dedicar-se a um universo que até então era delegado somente à figura masculina. Perceber as contribuições, mesmo que sutis, desta autora 
Rev. Interd. em Cult. e Soc. (RICS), São Luís, v. 6, n. 1, p. 23- 35, jan./jun. 2020

ISSN eletrônico: 2447-6498

que lutou para construir um perfil feminino ativo na província maranhense é valorizar não apenas a presença da mulher na literatura, mas na nossa cultura local e nacional.

$\mathrm{O}$ abandono dessa figura talvez se deva, principalmente, a razões ligadas à lei do patriarcado, em que, dependendo do gênero em que uma criança nascesse, teria já, de antemão, suas funções pré-definidas: à mulher caberia somente cuidar da família, ao homem cuidar dos negócios, de seu crescimento intelectual e exercer sobre tudo e todos do lar o pátrio poder. Todavia, Firmina se colocou acima dessa perspectiva limitante das atividades humanas ao gênero feminino. Sendo autodidata, revolucionou sua história e a história feminina maranhense, ainda que não seja reconhecida por seu talento.

Com ela, pela primeira vez, observa-se a construção de um personagem cativo que fala de sua condição sob um tom crítico e não passivo. Tal postura de discussão e reflexão Firmina tenta trazer para boa parte da sociedade leitora. Em suas obras, mesmo consideradas subversivas, os escravos tinham consciência daquilo que lhes acontecia e podiam dialogar, julgando as atitudes, ainda que não cometessem insurreições.

Maria Firmina dos Reis mostrou-se forte mesmo após sua morte. Por meio de suas palavras imortais, operou uma crítica que permanece, pois as estratificações sociais também permanecem. Ela mostrou-se resoluta, permanece atual e recorrente, ainda que tenha passado anos esquecida. Estudar e difundir seus feitos, atualmente, é uma forma de exaltar sua memória e sua importância, uma missão tenaz de todos os maranhenses, a fim de demonstrar que suas tentativas não foram insignificantes e sua voz merece e será ouvida.

\section{REFERÊNCIAS}

ADLER, Dilercy Aragão; VAZ, Leopoldo Gil Dulcio (orgs). Sobre Maria Firmina dos Reis. São Luís: ALL, 2015.

A poética no discurso do dominador: a permanência dos franceses no Maranhão na narrativa de D' Abbeville. Revista do IHGM. N.31-, novembro 2009 ed. Eletrônica. (128- 131). A mulher Maria Firmina dos Reis: uma maranhense. In: Maria Firmina dos Reis: faces de uma precursora. Rio de Janeiro: Malê, 2018.

CRUZ, Arlete Nogueira da. Sal e Sol. Rio de Janeiro: Imago, 2006.

DUARTE, Constância Lima; MORAIS, José Nascimento Filho. Maria Firmina: fragmentos de uma vida. São Luiz: COCSN, 1975. 
Rev. Interd. em Cult. e Soc. (RICS), São Luís, v. 6, n. 1, p. 23- 35, jan./jun. 2020

ISSN eletrônico: 2447-6498

LOBO, Luiza. Auto-retrato de uma pioneira abolicionista. Crítica sem juízo. Rio de Janeiro: Francisco Alves, 1993. p. 222-238.

MENDES, Melissa. A história hoje: gênero, representação e literatura a partir do romance Úrsula, de Maria Firmina dos Reis. In: CORREIA, Janaina. Revista Feminismos. Vol. 1, N.3, Set - Dez. 2013. Disponível em: www.revistafeminismos.neim.ufba.br.

MUZART, Zahidé Lupinacci (org). Escritoras brasileiras do século XIX: antologia. Santa Cruz do Sul: Ed. Mulheres/Edunisc, 2000.

NASCIMENTO, Camila Maria Silva. Dilercy Adler: a tecelã de Eros nos trópicos maranhenses. São Luís: Estação Gráfica, 2011.

NASCIMENTO, Camila Maria Silva; LIMA, Patricia Fernanda Massetti de. Maria Firmina dos Reis: uma maranhense. Anais do I Congresso Nacional de Linguística Aplicada e IV Encontro Nacional de Ficção Discurso e memória/Naiara Sales Araújo e Michelle de Sousa Bahury (orgs.). São Luís: EDUFMA, 2019.

REIS, Maria Firmina dos. Úrsula. São Luís, 1859. Fragmentos originais. Úrsula. Florianópolis: Edição digital. Belo Horizonte: PUC Minas, 2009.

RUFINO, Alzira; IRACI, Nilza; ROSA, Maria. Cartilha "Mulher negra tem História", 1987. Fonte: www.culturanegra.com.br.

SILVA, Régia. A mente, essa ninguém pode escravizar: Maria Firmina dos Reis e a escrita feita por mulheres no Maranhão. Leitura: Teoria e Prática, v.229, n.56, p. 11-19, 2011.

. A escravidão no Maranhão: Maria Firmina dos Reis e as representações sobre escravidão e mulheres no Maranhão na segunda metade do século XIX. São Paulo: Universidade de São Paulo, 2013. 